\title{
A course in dictionary use for Korean EFL teachers
}

\author{
Susanna Bae ${ }^{1}$
}

Received: 29 April 2015/Accepted: 9 June 2015/Published online: 15 July 2015

(C) Springer Berlin Heidelberg 2015

\begin{abstract}
This study examines knowledge needs for dictionary reference skills among Korean teachers of English within the context of a 12-h in-service teachertraining course in dictionary use. As an integral part of the curriculum development project, the study looked into various aspects of English teachers' dictionary training needs, mainly by means of multiple survey instruments (i.e., before- and after-training questionnaires) and the qualitative analysis of the teachers' duringcourse comments throughout multiple phases of the training process. The traineeteachers' spontaneous questions regarding dictionary use as well as their duringtraining feedback provided particularly useful information about the skills that should be focused on to meet the perceived training needs of current Korean teachers of English. The study has identified a clear need for typological and functional knowledge about the various dictionaries available, for informed dictionary choices, and for skills to exploit electronic dictionary functions. Most of the perceived needs were found to be related to across-dictionary skills, rather than skills specific to a particular dictionary. From this study, it was also found that explicit skill training can be a very effective mode of teaching for specific usergroups such as non-native teachers of English.
\end{abstract}

Keywords Dictionary reference skills · Teacher training - Curriculum development $\cdot$ Needs analysis

Susanna Bae

susannabae@gmail.com

1 International Graduate School of English (IGSE), 17 Yangjae-daero 81-gil, Gangdong-gu, Seoul, South Korea 


\section{Introduction}

When it comes to the training of foreign language teachers in dictionary use, we can suppose the following three possibilities: (1) teachers need to be informed of dictionary usage skills which their students need to learn; (2) teachers need instructional strategy training for facilitating students' learning of these target skills in classrooms; and (3) teachers need training in skills and strategies which they need for their own language development. Although these three objectives may be closely intertwined, the first two are directly related to the improvement of students' learning, thus understandably deserving more immediate priority. As to the last one, its purpose and viability seem less obvious in general teacher-training contexts until we turn to what research, albeit very limited, tells us about teachers' actual reference competence.

Generally speaking, foreign language teachers are regarded as the ones who teach, rather than who are taught, how to use dictionaries. When dictionary researchers address language teachers, they usually see them as 'additional mediators' (Hartmann 2001: 26) between themselves and the students, or as informants who give their opinions about their students' use of dictionaries. This assumed role of language teachers as mediators or transmitters of knowledge often obscures the actual reality which research has revealed that teachers are not extremely different from their pupils in terms of dictionary training (Bae 2011). Teachers are not absolutely confident about their dictionary-using skills and are often uncertain about how to make the most of dictionaries for effective language use and language teaching. English teachers' lack of familiarity with particular dictionary codes in older editions of monolingual learners' dictionaries was pointed out as early as 30 years ago (Whitcut 1986). More recent studies with non-native English teachers also show that teachers sometimes feel uncomfortable with new functions available in electronic dictionaries (Ozawa and Ronald 2009) and they often fail to keep up with newly developed lexical resources (Bae 2011). Furthermore, studies carried out in Hong Kong (Chi 2011) and South Korea (Oh 2006) confirmed that Chinese and Korean teachers rarely receive any form of systematic instruction in dictionary use. Such evidence supports the idea that teachers of English as a foreign language can and should be a distinctive target group in its own right for dictionary skills instruction.

The course which is presented in this report was developed on this premise: there are certain dictionary-related skills of which explicit learning and awareness-raising are beneficial to EFL teachers' own linguistic progress and professional development. It should first of all be acknowledged that skills for teachers may be quite different from those for students who are still developing linguistically and cognitively. A couple of questions then remain: what kinds of dictionary skills do EFL teachers need and how can we assess their needs for training?

The issue of what constitutes dictionary reference skills has never been settled (Lew 2013); however, there is a general agreement that dictionary skills consist of multiple dimensions of knowledge and skills, including knowledge of various dictionary types and functions, the ability to critically evaluate them, and decision- 
making strategies as how to exploit them (Herbst and Stein 1987; Béjoint 1989; Horsfall 1997; Nesi 1999; Scholfield 1999). Skills may even include language learning strategies related to dictionary use, such as recording or storing dictionary information for vocabulary learning enhancement (Nesi 2010). These skills are quite different from the context-specific macro- and micro-level reference skills which have been most frequently referred to in the teaching of dictionary use (Stark 1990).

Another point to be acknowledged is that EFL teachers are far from being a homogenous group. As Chi (2003: 4) points out, with massive and diversified user characteristics - even within the teacher group boundary-it would not be easy to reach a consensus on what to include in a dictionary teacher-training curriculum. English teachers in some Asian contexts may differ greatly from those in other Asian regions in terms of their use of, and attitudes toward, dictionaries. The third factor that adds to the complexity of identifying dictionary skills needs of EFL teachers is related to the environment in which most EFL teachers are involved. In spite of the undeniable role dictionaries play in the learning of a foreign language, current ELT practices pay only scant attention to the teaching of dictionary skills, relegating skill development solely to the language learner. This lack of attention resulted in the near absence of dictionary pedagogy in the EFL discourse, and teachers do not seem to readily perceive the need for any type of specific training in dictionary use. As long as the dictionary is taken for granted by the teachers, one-off and context-detached surveys may not effectively capture what skills they actually need.

The present study was motivated by the recognition of this current state of affairs in regards to teacher training in dictionary use. The present situation indicates that the identification of teachers' reference needs requires a systematic analysis process. That is, an investigation into training needs should encompass necessities (i.e., what teachers should know), lacks (i.e., what they do not know), and wants (i.e., what they want to know) (Hutchinson and Waters 1987; Richards 2001; Nation and Macalister 2010). Existing research suffers a serious lack of information in all these aspects. Research evidence is limited in terms of teachers' skill deficiencies whereas general dictionary training curricula do not fit this group. In particular, the target user's subjective needs or wants are one of the considerations that the dictionary training literature has most seriously neglected. The current situation also indicates that the process of needs analysis may be best facilitated by a sustainable training context in which these various perspectives of needs can be explored in depth and over time with specific users.

The present study has the aim of discovering the dictionary training needs of Korean teachers of English and their attitudes toward such training. For this purpose, it adopted an exploratory curriculum-based framework with multiple training phases and multiple participant cohorts. It takes the view that the training course itself can be a locus of close investigation into the complex issues relating to the teaching of dictionary skills. The following research questions guided this study:

(1) What are the training needs of Korean teachers of English in terms of dictionary reference skills?

(2) How do teachers respond to the dictionary skills training course? 
Section 2 provides an outline of the overall research framework, followed by the process of establishing the target skill inventory and the course syllabus. The main data collection methods are described in Sect. 3. After discussing the results in Sect. 4, the paper concludes with their implications for future teacher-training practice in dictionary use.

\subsection{Outline of research framework}

The research project took place in 2011 and 2012 as an in-service teacher-training course in dictionary use for Korean public-school teachers of English, designed and offered by me, at a teacher-training institute located in Seoul, South Korea. The training course involved four groups of secondary-school, and three groups of primary-school English teachers (comprising seven groups of 85 teachers in total), throughout three academic terms. Overall, the project consists of the course implementation and the research undertaking; it also includes multiple phases of needs analysis with multiple data collection instruments such as pre-course survey, during-course teacher-trainee feedback, and delayed follow-up questionnaire. Figure 1 summarizes the whole project processes:

\section{Course development} procedure

\section{Preliminary set of target dictionary skills}

\section{Preliminary} course syllabus<smiles>C1=CCC1</smiles>

Training

[6 months later]

Revision of syllabus

$\&$

Re-implementation

\section{Data collection}

procedure

Pre-course survey with

an open-end question

During-course

session feedback

\section{Delayed follow-up questionnaire}

Fig. 1 Flowchart of course development and data collection 
While some of the procedures were carried out once at a specific point in time, some others were recursively implemented throughout a stretch of 2-year time with different teacher groups. Also what should be mentioned here is that the study involved the repeated administration of the same data collection methods across the groups. The pre-course survey and during-course feedback, for example, were collected from the seven groups of teachers on different time lines. The delayed follow-up questionnaire, on the other hand, was only administrated to the first four teacher groups. With this variability in mind, the present paper tried to synthesize the overall results without compromising the reliability of data interpretation.

\subsection{Course development: target skills}

The first step in the course development was to establish a set of dictionary skills for the target group. The target skill selection process mainly involved literature review of dictionary skills including those for electronic dictionaries. At the same time, I briefly examined the wider context in which the course was situated in order to ensure its relevance to target trainees. Informal focus group questioning also followed.

Prior literature reveals that the term, dictionary reference skills, has been very loosely defined (Cowie 1983; Hartmann and James 1998; Nesi 1999), and its perspectives have been expanded through time-from the most typical productoriented viewpoint as user requirements to a more user-centered notion which emphasizes greater choice and control. Among attempts to classify dictionary reference skills (Whitcut 1986; Herbst and Stein 1987; Moulin 1987; Béjoint 1989; Bogaards 1993; Scholfield 1982, 1999; Nesi 1999; Nation and Paul 2013), the skill inventory proposed by Nesi (1999) provides the most exhaustive list of relevant skills based both on document analysis and empirical evidence. Therefore, it was thought to provide a basis for the further specification process of dictionary skills for the target group.

Although Nesi's inventory does include some electronic dictionary functions such as the use of wildcards and hyperlinks, the growing sophistication of various forms of electronic dictionaries makes it necessary to add new functions and skills. An array of advanced search functions is comprehensively introduced in Pastor and Alcina (2010) and de Schryver (2003) against which corresponding user skills could be drawn. Another important point of consideration in selecting electronic reference skills was the differentiation between types of electronic dictionaries in terms of user-interface and current popularity among Korean users. While on-line dictionaries have greater usability, stand-alone electronic dictionaries have greater search facilities and stability (Pastor and Alcina 2010), thus its relative competitiveness needed to be considered.

In order to have a glimpse of how the dictionary is viewed by those in ELT communities, I examined the Korean national curriculum of English and textbooks, commercial materials for English learning, as well as dictionary-related postings in an on-line question-and-answering forum (kin.naver.com). While the national curriculum and English textbooks only haphazardly dealt with a couple of very rudimentary dictionary skills, dictionary users seemed to seek for practical answers to 
their dictionary-related questions from informal sources, such as advice from anonymous on-line Q\&A forums where the quality and accuracy of the answers is open to question (Fichman 2011). Published ELT materials were found to be even more problematic. A brief analysis of three commercially successful English materials, which had separate sections about dictionary use, confirmed that dictionary advice provided by these materials was even more erroneous and misleading than the anonymous postings in the web forum. A notable example was found in a bestseller (Jeong 1999): the author of the book prescribes that the reader must use only COBUILD dictionary, and spend $1 \mathrm{~h}$ every day copying the definitions and example sentences of every unknown word into his or her notebook. Another English learning material (Lee and Lee 2006) written for Korean mothers of young children claimed that children should start using monolingual English dictionaries once they become able to read the English alphabet. Although they might not represent general public's view about dictionaries, the lack of understanding shown from these claims is quite telling.

The results of the pilot questioning with approximately 20 English teachers (who were not the trainee-teachers for this study) also yielded considerable evidence for potential dictionary training needs in certain skill areas: questions were most often related to the choice of English dictionaries and the benefits of dictionaries for English language learning.

These results indicate that a balanced view about dictionary use should be disseminated among the general public, but first and foremost, among language teaching professionals such as English teachers. In view of the results obtained from the preliminary analysis, a list of skills potentially relevant to the target traineeteachers was established. It consisted of thirty items and each item was classified in the Nesi's (1999) six categories (see Appendix 1).

\subsection{Course development: syllabus}

Apart from minor differences in English proficiency, the participant trainee-teachers had a great deal in common: using Korean as their native language, educational background, and extensive teaching experience. The dictionary course, titled as 'English dictionaries for EFL teachers', was set up as one of the compulsory courses provided by the institute, along with 'teaching English through drama', 'computer assisted language learning', 'task-based learning and teaching', etc. As the institute decided that the dictionary course be delivered in four 3-h weekly sessions, the course's content and activities were adjusted so that they could be carried out within the 12-h time allocation. Thanks to the sponsorship of major dictionary distributors, each class could work with five to six copies of the major English dictionaries. The dictionaries mainly used include the following titles: OALD English-Korean, current editions of OALD, LDOCE, COBUILD, and MEDAL, Oxford Collocations Dictionary, Macmillan Phrasal Verbs Plus, Oxford Learner's Thesaurus, Oxford Picture Dictionary, Longman Essential Activator, and Neungryule Junior English Dictionary. Other popular dictionary websites were also introduced during the session for electronic dictionary use. 
In developing the course syllabus, the modular approach was loosely adopted by breaking down the course into more or less independent non-linear units (Nation and Macalister 2010: 85). Within the 4-week timeframe, each session was developed with a clear distinctive focus in topic areas as in the following sequence (Table 1).

The new concepts and knowledge to be introduced in each session were consciously arranged to maximize understanding and assimilation without

Table 1 Four-week syllabus of the course in dictionary use

\begin{tabular}{|c|c|c|}
\hline \multirow{6}{*}{$\begin{array}{c}\text { Week } \\
\text { one }\end{array}$} & Topic & Awareness-raising \\
\hline & Content & The trainee-teachers reexamine widely circulated notions about dictionaries \\
\hline & & $\begin{array}{l}\text { They also examine the most common patterns of misuse by average dictionary } \\
\text { users }\end{array}$ \\
\hline & & $\begin{array}{l}\text { They express their own beliefs and opinions about English dictionaries (i.e., } \\
\text { monolingual vs. bilingual; electronic vs. print dictionaries) and review their } \\
\text { opinions in light of what has been found in dictionary research }\end{array}$ \\
\hline & & $\begin{array}{l}\text { They are informed of the areas of dictionary skills and discuss which skills they } \\
\text { think are most relevant to their students }\end{array}$ \\
\hline & $\begin{array}{r}\text { Target } \\
\text { skills }\end{array}$ & 1. (1), 1. (2), 3, 4, 6, 7, 25, 28, 30 (see Appendix 1) \\
\hline \multirow{6}{*}{$\begin{array}{r}\text { Week } \\
\text { two }\end{array}$} & Topic & Understanding dictionary structures and content \\
\hline & Content & The trainee-teachers learn the mega-, macro-, and micro-structures of dictionaries \\
\hline & & $\begin{array}{l}\text { They look closely into what is contained in the Oxford English-Korean } \\
\text { Dictionary in book form }\end{array}$ \\
\hline & & They also learn dictionary conventions and their meanings \\
\hline & & $\begin{array}{l}\text { They compare entries from different dictionaries of the same functionality and } \\
\text { discuss ways to select the most appropriate dictionaries for particular user } \\
\text { levels }\end{array}$ \\
\hline & $\begin{array}{r}\text { Target } \\
\text { skills }\end{array}$ & 2. (1), $5,8,11,15,16,17,19,20,21,22,23,26,27$ \\
\hline \multirow{4}{*}{$\begin{array}{l}\text { Week } \\
\text { three }\end{array}$} & Topic & Using English dictionaries for production \\
\hline & Content & $\begin{array}{l}\text { The trainee-teachers have opportunities to undertake language activities using } \\
\text { major English learners' dictionaries specifically for production }\end{array}$ \\
\hline & & $\begin{array}{l}\text { After reviewing major productive learners' dictionaries, they discuss the } \\
\text { perceived merits and limitations of each of the dictionaries and share ideas on } \\
\text { how to make use of them for their teaching, learning, and communication }\end{array}$ \\
\hline & $\begin{array}{r}\text { Target } \\
\text { skills }\end{array}$ & 1. (3), 1. (4), 1. (5), 2. (2), 26 \\
\hline \multirow{5}{*}{$\begin{array}{r}\text { Week } \\
\text { four }\end{array}$} & Topic & Using electronic dictionaries \\
\hline & Content & $\begin{array}{l}\text { The trainee-teachers undertake language activities using dictionaries on CD- } \\
\text { ROM }\end{array}$ \\
\hline & & Dictionary portals and specialized on-line dictionaries are also introduced \\
\hline & & $\begin{array}{l}\text { The teachers explore various kinds of advanced search techniques and discuss } \\
\text { their pedagogical applications }\end{array}$ \\
\hline & $\begin{array}{l}\text { Target } \\
\text { skills }\end{array}$ & 1. (6), 2. (3), $5,9,10,12,13,14,15,18,23,24,29,30$ \\
\hline
\end{tabular}


overloading the trainee-teachers. For instance, the awareness-raising session would provide a sense of direction and purpose when the teachers learned new, more specific knowledge about dictionaries. The typological and structural knowledge about general English dictionaries acquired in the second session would lead to better appraisal of English dictionaries for production in the next session, and so on. In a similar vein, some target reference skills were covered recursively (e.g., skills $5,23,26$, and 30) so that they would be better assimilated throughout training as the teachers try out dictionaries of different kinds.

\section{Data collection}

This study utilized mainly three data collection methods: (1) a pre-course survey with an open-end question, (2) trainee-teachers' during-course session feedback, and (3) a delayed follow-up questionnaire. In the following sections, the procedures for each data collection instrument are presented.

\subsection{Pre-course survey and open-ended question}

The pre-course survey was administered to the trainee-teachers in order to understand the general relationship they have with their English dictionaries and their specific needs for dictionary training. The questionnaire included the following categories of enquiry: (1) teachers' dictionary-using habits; (2) teachers' experiences of dictionary instruction; (3) teachers' opinions about the use of electronic dictionaries; (4) teachers' knowledge about some electronic search techniques, and (5) a question regarding teachers' perceived needs for dictionary knowledge.

The last question category, which is about teachers' perceived needs for dictionary knowledge, involved an open-end question (i.e., "Please write up to three questions that you are most curious about dictionary use or dictionary instruction."). Asking respondents about areas of concern or curiosity regarding dictionary use may reveal unexpected dynamics between the dictionary and the user, from which we can grasp implications for the orientation of the teaching of dictionary use.

The pre-course survey was administered at the beginning of each class by distributing the printed survey sheets in the classroom. 81 teachers responded to the survey. The frequency of the responses was calculated descriptively. When necessary, responses across groups and questionnaire items were cross-tabulated in order to detect any emergent correlations. The survey questions consist both of 'yes or no' questions and ordinal scales, thus the group differences in responses were tested using non-parametric group difference tests (Pearson $\chi^{2}$ and Fisher's Exact tests for 'yes-no' questions, and Kruskal-Wallis test for rating scales). No significant group differences were detected.

\subsection{During-course session feedback}

The during-course session feedback was used to assess the trainee-teachers' needs in an ongoing way. The participants' feedback was obtained by means of a 
structured template for written responses, which was adapted from Carduner's (2003) feedback form. The session feedback form was administered at the end of each class, partly because the duration of the training course was fairly short (4 weeks); but more importantly because this was intended to be a type of ongoing evaluation of the needs of the participant trainee-teachers. By regularly eliciting the trainee-teachers' feedback, it was expected to assist them to reflect on each session's content so that I could receive their evaluations about specific skill items and topics covered in specific sessions. The feedback form was constructed as in Fig. 2

The data gathered from the during-course feedback were qualitative in nature, involving the participants' written responses. In order to find salient thematic patterns and their magnitude, the qualitative data processing software, the NVivo version 10, was utilized. The analysis of the teachers' feedback went through several coding stages. First, the teachers' written comments were transcribed, or translated if they were written in Korean; and then the transcribed data were imported to separate Excel spreadsheets according to class group and session period, and then again exported to the NVivo program. To the question of selecting the most appropriate coding methods for the analysis of the session feedback, the structural coding proposed in Saldaña (2009) was adopted. This approach is considered to be suitable when dealing with semi-structured datasets involving multiple participants. The template of the form was intended to elicit the participants' feedback mostly in terms of the perceived usefulness; it therefore provided the basic structure of positive/negative reactions from which more elaborate thematic analysis could be developed.

\section{Session Feedback Form}

Please respond honestly and constructively to the questions below by writing brief comments (either in English or in Korean).

1. What you found most useful in today's session was (were)..

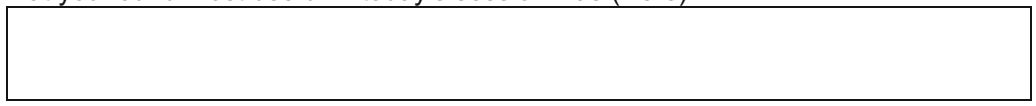

2. What you found least useful in today's session was (were)...

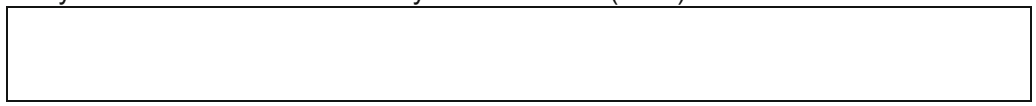

3. Please write anything you want to ask or comment (what remains unclear to you, your suggestions, etc.):

Fig. 2 During-course session feedback form 
In total 718 written comments were collected. The participants' feedback was coded in terms of three different dimensions: (1) opinions; (2) skill areas; and marginally, (3) comments about specific dictionaries. First, the trainee-teachers' opinions refers to their reactions and evaluations about what they learned; this category of feedback therefore provide the most important information about their reference needs. On the other hand, 'skill areas' refers to specific lesson topics about which the trainee-teachers expressed their opinions. Lastly, codes under the category of 'comments about specific dictionaries' refer to the specific dictionaries or dictionary types the participants were commenting on. The last two properties are more like topical attributes than participants' opinions proper, in that they assign contexts for analysis and interpretation in order to see about which lesson topic or dictionary the trainee-teachers expressed their opinions. The analysis revealed that the participants mainly commented on the following eleven lesson topics:
A: Comparing entries
B: Dictionaries for production
C: Discussion on dictionary reference skills
D: Using electronic dictionaries
E: Awareness-raising
F: Mega-structure of a print dictionary
G: Overview of dictionary types and functions
$\mathrm{H}$ : Symbols and discourse features of dictionaries
I: //Grammatical symbols (as a sub-topic of $\mathrm{H}$ )
$\mathrm{J}$ : Terminology and lexical concepts
$\mathrm{K}$ : //What are collocations (and the collocations dictionary)? (as a sub-topic of J).

The participants' reactions, evaluations, and opinions were classified into a total of 32 code properties, and they were organized in terms of their thematic relations and hierarchy (for a summary of code properties and their frequencies, see Appendix 2).

\subsection{Delayed follow-up questionnaire}

The overall evaluation of the training course and its potential as a teacher development program was carried out using the delayed follow-up questionnaire. The follow-up questionnaire was administered 6 months after the trainee-teachers completed the course-when they had already returned to work and spent a semester with their students. It was quite delayed in time, considering course evaluations in general are carried out at the end of the term. Unlike this common approach to course evaluation, it deliberately gave a sufficient interval between the termination of the training course and the administration of the questionnaire in order to elicit evaluation from the participants about the impact of the training course on their teaching practice.

Investigating the impact of a training course may be different from measuring the efficacy, or more generally, the effect of the course. While the latter measurements focus on participants' learning outcome, the former focuses on other aspects such as 
whether it has influenced the participants' behavior and attitudes and whether it has brought about any changes to their teaching practice. The course in this study was evaluated in terms of five aspects: (1) change of behavior, (2) perceived increase in knowledge, (3) perceived change in attitudes, (4) course's relevance to teacher development, and (5) participants' willingness to recommend it to colleagues. The delayed follow-up questionnaire consisting of 18 questions was distributed in January 2012 via an Internet-based survey instrument. Thirty-four out of the 48 teachers $(71 \%)$ responded.

\section{Results and discussion}

This section first presents the characteristics of the trainee-teachers in terms of their dictionary-using habits and their experience of dictionary instruction. Then, the two main research questions are treated. The findings derived from the three different datasets are integrated in view of the research questions to give a clear view of the teachers' skills and training needs.

\subsection{Teachers' dictionary use}

The respondents in the pre-course survey are frequent users of English dictionaries with the majority (59\%) using dictionaries 5 days or more per week. As to the types of dictionaries they use, on-line dictionaries and dictionary apps in mobile phones are found to be the two most popular reference tools, followed by hand-held personal electronic dictionaries (PEDs). Dictionaries on CD-ROM are the least popular dictionary type among the teachers; over $70 \%$ had "never" experienced using one. The trainee-teachers were not aware of the diverse functions and facilities of dictionaries on CD-ROM, and their educational potential as a vocabulary teaching resource was not recognized. The print dictionary was second least often used by the teachers. More than half of the teachers $(50.6 \%)$ reported that they do not use print dictionaries any more.

Although PEDs was ranked as the third most frequently used dictionary type by the teachers, the responses show a more scattered pattern of use than in the other dictionary types. For one thing, the teachers who never use PEDs (26 teachers, $32 \%)$ are as many as those who use them often (27 teachers, $33 \%)$. Similarly, the number of teachers who responded that they "seldom use PEDs" is the second largest next to that for print dictionaries (14 and 22, respectively). Considering that there is less chance that PEDs are shared with other people or provided as library stock, as in the case of paper dictionaries, the number of responses from those teachers who might own PEDs but seldom use them does not look negligible. In brief reliability-check interviews followed by the survey, some of the teachers said that they do not use PEDs "anymore" because they can use mobile dictionary apps on their smart-phones. PEDs, which have long been acknowledged as very handy and convenient reference tools especially in some Asian countries, seem to have been superseded by mobile dictionary apps. 


\subsection{Teachers' experience of reference skills instruction}

The survey asks if the teachers have ever received or given formal instruction in dictionary use. Regarding the teachers' experience of receiving formal instruction in dictionary use, the vast majority ( 75 teachers, $92 \%$ ) of the respondents answered that they had not received any form of dictionary instruction. For those who responded "yes," the instruction they had received was mostly about locating headwords or interpreting morphological/word class abbreviations.

As for the teachers' own classroom instruction in dictionary use, more than 20 percent (17 teachers in all) claimed that they taught their students how to use dictionaries on a regular or an occasional basis. Even though this figure is larger than the number of the teachers who had received instruction in dictionary use themselves, those who never or only seldom taught their students how to use dictionaries still comprised the majority $(79 \%)$. Similar to the instruction they had received, "finding headwords" is the single skill item which was most often taught in the classroom, comprising eight out of a total of 25 instances. Skills other than locating headwords and interpreting grammatical/phonetic symbols were seldom taught. Interestingly, there were two mentions relating to the issue of vocabulary learning through dictionary use. One teacher reported teaching how to "record looked-up words in on-line dictionaries for revision". Another teacher reported telling her students that "it is sometimes better to get a clearer idea about an unknown word by looking it up in a dictionary". Still another teacher said that he just told students to become familiar with a dictionary or two by carrying one in school - one of the most passive form of dictionary skill instruction (Scholfield 2002).

\subsection{Teachers' needs for dictionary knowledge and skills training}

The teachers' needs were identified from the following aspects: first, the teachers' degree of familiarity with specific electronic search facilities was examined through the pre-course survey; their spontaneous needs for dictionary knowledge (i.e., what they are most curious about, or they want to know) and their general expectations about the training course were examined through their responses to the open-ended question in the survey; and lastly, the teachers' perceived usefulness about particular skills was captured through during-course monitoring via the teachers' written feedback.

\subsubsection{Teachers' electronic dictionary use}

The participants' awareness of electronic search functions was measured in terms of frequency of their use. "Voice pronunciation" was the most widely used function (with a mean score of 1.11), followed by "cross-referencing by hyper-linking" and the "tool-bar/minimal display" function. Only in these three areas did more than half of the trainee-teachers claim to use. On the other hand, wildcards, Boolean search, and advanced search functions are ranked as the three least used search facilities by the respondents. Table 2 gives a summary of the results: 
Table 2 Teachers' frequency of use of electronic search functions

\begin{tabular}{lrrlllr}
\hline & $N$ & Mean & Std. deviation & $\mathrm{N}(0)$ & $\mathrm{N}(1)$ & $\mathrm{N}(2)$ \\
\hline Q6. How often do you use these functions? & & & & & \\
Boolean searches & 80 & .48 & .656 & 49 & 24 & 7 \\
Wildcards & 80 & .23 & .477 & 64 & 14 & 2 \\
History function & 80 & .64 & .733 & 41 & 27 & 12 \\
Voice pronunciation & 80 & 1.11 & .711 & 16 & 39 & 25 \\
Advanced searches & 80 & .55 & .692 & 45 & 26 & 9 \\
Tool-bar/mini-dictionary functions & 80 & .71 & .697 & 34 & 35 & 11 \\
Cross-referencing by hyper-linking & 80 & .73 & .763 & 37 & 28 & 15 \\
\hline
\end{tabular}

Missing answer: $1 ; 0=$ never, $1=$ sometimes, $2=$ often

In the case of "advanced searches", although more than 40 percent (35 out of 80 teachers) claimed that they sometimes or quite often used some of the techniques, a further clarification check revealed that many of these search techniques were "Google image search", "cross-referencing for synonyms" or "clicking on the "more example sentences' menu" - search functions which are transparent and quite self-explanatory. On the other hand, more sophisticated techniques such as thematic search, right-core field search, or multi-media search, etc. are less likely to be picked up incidentally, indicating the need for explicit training.

\subsubsection{Teachers' spontaneous needs for dictionary knowledge}

Responding to the survey's open-ended question, the teachers sent a total of 126 dictionary-related questions. Their questions were categorized into the following six themes based on Nesi's (1999) taxonomy: (A) classroom teaching of dictionary use; (B) language learning through dictionary use; (C) pre-use dictionary skill; (D) while-use dictionary skills; and (E) understanding lexicographical issues. The first two themes are those which newly emerged through the analysis of the teachers' enquiries, except that 'Stage 5: recording entry information' (Nesi 1999) was relocated under the theme of 'B. Language learning and dictionary use.' The skills under the categories in 'Stage 1: before study' and 'Stage 2: before dictionary consultation' (Nesi 1999) were subsumed under 'C: Pre-use dictionary skills'. Similarly, 'Stage 3: locating entry information' and 'Stage 4: interpreting entry information' were merged to form 'D: While-use dictionary skills'. Lastly, 'understanding lexicographical issues' remained basically the same as the 'Stage 6' skills in the original taxonomy. The 126 enquiries made by the teachers were coded according to the above scheme and their frequency and patterns were calculated using NVivo10. Some of the teachers' questions were given more than one code property, thus the total number of coding references was 135 . Figure 3 gives a summary of question topics with their frequency distribution.

As can be seen in Fig. 3, the three most frequently asked categories were the preuse dictionary skills, classroom teaching of dictionary skills, and language learning 


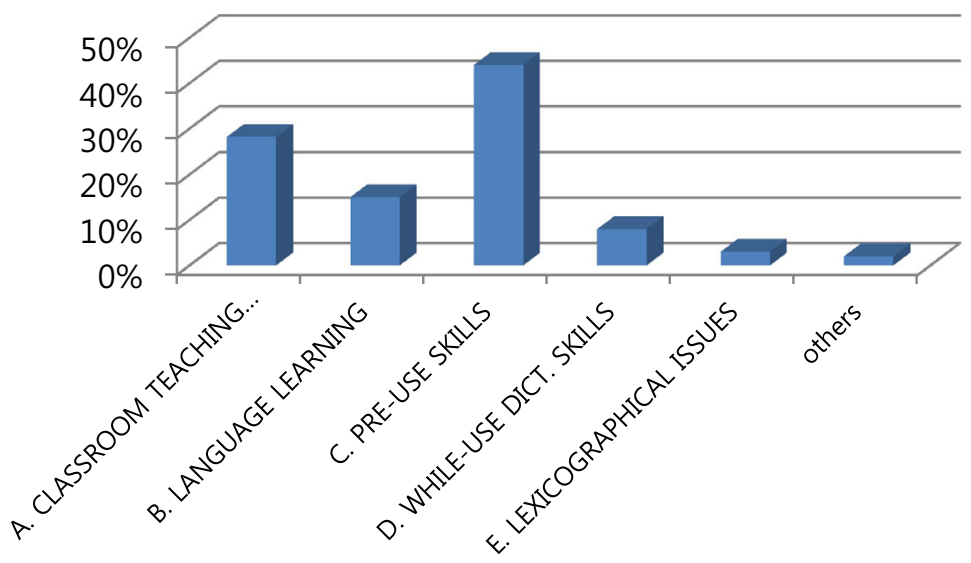

\begin{tabular}{lcc}
\hline Thematic category & Percentage & Frequency \\
\hline \hline A. Classroom teaching of dictionary reference skills & $28 \%$ & 38 \\
B. Language learning through dictionary use & $15 \%$ & 20 \\
C. Pre-use skills & $44 \%$ & 60 \\
D. While-use dictionary skills & $8 \%$ & 10 \\
E. Lexicographic issues & $3 \%$ & 4 \\
Others & $2 \%$ & 3 \\
\hline
\end{tabular}

Fig. 3 Teachers' question topics by thematic coverage and frequency

through dictionary use. The 60 references coded as 'pre-use dictionary skills' include those coded as 'choosing dictionaries' (25 instances), 'best dictionary request' (15 instances), and 'knowing types of dictionaries' (11 instances). They all deal with the question of 'whether and when to use which dictionary'. When we further analyze the teachers' questions about the choice of dictionaries, it is clear that these questions very often concern dictionary choice appropriate to user level, between print and electronic dictionaries, and between monolingual and bilingual dictionaries. The summary below shows the most representative examples of the teachers' questions coded as being related to pre-use dictionary skills:

- When people use a dictionary for the first time, what dictionary should they use?

- Nowadays a lot of people use an electronic dictionary. Is it helpful to use a paper dictionary?

- Some of my friends, who are native English speakers, say that Korean-English dictionaries are incorrect. Then should I only use an English-English dictionary?

- What English dictionary is the most helpful for the third-year high school students?

- What Internet dictionary websites are good?

- Which dictionary publisher is best?

- Is there a dictionary which shows the meaning differences between synonyms? 
- Is there a dictionary that shows how frequently a certain word is used?

- When I run into a new word, should I look it up in a dictionary immediately?

All these examples reflect the ever growing difficulties users experience when choosing from among the hundreds of different dictionaries available. The traineeteachers' confusion about the choice between monolingual and bilingual dictionaries may also reflect the dilemma of Korean teachers of English. It seems that the widespread emphasis on using monolingual dictionaries and the criticism of bilingual dictionaries strongly influence Korean-English teachers, yet they are aware that using only monolingual dictionaries is not realistic even for themselves, not to mention their students. It seems that they want clearer guidance in this matter.

The second most frequently asked question topic was 'the classroom teaching of dictionary reference skills', apparently due to the particular context of this study. Overall 38 questions were classified in this theme. The teachers' questions could be divided into two broad sub-categories: a) how to teach the skills to their students (32 instances); and b) uncertainty about the teaching of such skills (i.e., why teach at all, three instances). 'How to teach' includes requests for teaching plans and readymade activity guides for classroom use. The third most frequently coded theme was 'Language learning through dictionary use', comprising 20 reference instances. The effect of using particular types of dictionaries was also a frequently asked topic by the teachers, as in the following:

- Is it helpful to use a thesaurus a lot?

- How can I improve my English with an English dictionary?

- Does the frequent use of a Korean-English dictionary inhibit English learning?

- If I keep doing further searches for words such as synonyms and collocations, am I wasting time in class?

- Is using an English dictionary really helpful for students? Using a dictionary could be a burden to some students.

In an educational environment such as South Korea, where exposure to English is mostly limited to classrooms, consulting a dictionary for unknown words may well be regarded as ineffective and time consuming, especially when learners can succeed in communication just using the glossaries provided in textbooks or vocabulary learning materials. Considering such circumstances, it is telling that most questions under this category were about finding a balance between the reference purpose and the learning purpose when using dictionaries, including the matter of the extent to which one should pay attention to dictionary information. Since using dictionaries is perceived as considerable cost (extra time and effort) inflicted upon the user, looking up words in a dictionary can entail the learner's decision to pay specific attention to particular words in the expectation of better learning. Even though using dictionaries is very often regarded as a passive strategy for vocabulary learning (Harmer 2001), for Korean learners of English at least, it seems to require rather active learner involvement, and this involvement is in turn expected to result in better learning of the target words. 


\subsubsection{Teachers' perceived usefulness of dictionary reference skills}

In this section, I will discuss how the trainee-teachers' dictionary knowledge needs were recognized through the session feedback and how the training course contributed to the teachers' learning of dictionary knowledge and skills. Overall, as can be seen in Appendix 2, the training course was received fairly favorably by the teachers, with an overwhelmingly greater number of positive evaluations (563) than negative (140). Particularly, the course was found to have positively affected the teachers' acquisition of dictionary skills and knowledge. 'Knowledge and skills increased' (218) and 'New knowledge gained' (65) are the properties relating to the knowledge aspect of the teachers' learning outcomes, and these combined had the greatest numbers of coding references.

Some dictionary knowledge turned out to be new to the teachers, and such instances were coded as 'New knowledge gained.' The teachers' enthusiasm for learning new knowledge was particularly strongly expressed during the sessions where they explored productive dictionaries and learned the functionalities of electronic dictionaries. It was found that special productive purpose dictionaries (i.e., activators, collocation dictionaries, and learner's thesaurus) were seldom known, let alone used, by the teachers, and many of the teachers were impressed by the advanced search techniques available in various electronic dictionaries. Some of them described the newly gained insights and knowledge about dictionaries as 'discovering a new world': "I explored these dictionaries. Eureka! I felt like Columbus just when he discovered the new world." [a comment from a primaryschool teacher]; "I didn't know electronic dictionaries have such a lot of useful functions-it was like I found a whole new world!" [a comment from a secondaryschool teacher].

Another very frequently found positive feature was 'Perspective modified' (87), which is related to the attitudinal aspect of the teachers' learning outcome. It was found that the course helped the teachers reappraise their perspectives and attitudes toward English dictionaries. It was often observed that most of the trainees in their first sessions did not readily accept the idea that they are here to develop their own dictionary skills. In other words, the purpose of the dictionary course was not easily understood. However, as the training course proceeded, many of the teachers started to recognize their knowledge needs. One made the following comment: "At first I had a very vague idea about this course, but through the sessions, I came to realize the importance of the dictionary." [a comment from a secondary-school teacher]. The course was also found to have stimulated the teachers' motivation to use dictionaries, as indicated in the number of coding references for 'Motivation increased' (37).

On the other hand, the teachers' negative evaluation was mostly due to the difficulty ('Difficult', 38 comments) and the amount of course content ('Excessive amount of course content', 25 comments). The perceived difficulty sometimes gave the teachers the uncomfortable feeling that they did not clearly understand the lesson ('Unclear', 16 comments). The lack of immediate relevance to their own teaching practice was another major drawback the teachers mentioned ('Not relevant to classroom teaching', 17 comments), and this was also related to the 
teachers' demand for more readily recyclable classroom materials in dictionary use ('Expectations about the course//Dictionary activities', 9 comments).

Analysis by skill areas enabled me to further investigate the relative usefulness between the skills covered in the course. Table 3 provides a summary of the trainees' positive and negative feedback according to the skill areas.

Table 3 shows that electronic search techniques ('D: Using electronic dictionaries') were the most useful skill area, followed by the three skill areas: 'G: Overview of dictionary types and functions', 'B: Dictionaries for production', and 'A: Comparing entries'. The lesson on electronic search techniques was found to be the most useful from almost every point of view, not only because these techniques were "new" and "useful" for English language learning and teaching, but also because they were "fun" to learn and highly "motivating". The activities with major productive-purpose learners' dictionaries were also received favorably, presumably because of the novelty factor (16 references coded as 'New knowledge gained'). Awareness-raising activities with discussions of the most effective use of dictionaries were found to be a useful way for the teachers to reappraise their attitudes toward dictionaries (20 references coded as 'Perspective modified'). Other skill areas which received moderately favorable evaluations were ' $F$ : Megastructure of a print dictionary' and ' $\mathrm{H}$ : Symbols and information features of a dictionary'. The teachers found these topics useful for increasing their dictionary competence, although no one found them enjoyable - none of these skill areas were assigned to the coding property, 'Fun activities'.

In short, the learning of dictionary skills was most successfully promoted in the following four skill areas: electronic search techniques, dictionary types and functions, using productive dictionaries, and dictionary evaluation. The teachers expressed the least interest in the lesson topics which discussed various dictionary skills and introduced dictionary conventions and terminology. The teachers also felt that these skills were the most difficult. However, collocation (and retrieval and interpretation of collocation information in a dictionary) met with considerable

Table 3 Overview of positive and negative feedback on skill areas

\begin{tabular}{lcc}
\hline Skill areas & Positive feedback & Negative feedback \\
\hline A: Comparing entries & 50 & 3 \\
B: Dictionaries for production & 51 & 2 \\
C: Discussion on dictionary reference skills & 3 & 13 \\
D: Using electronic dictionaries & 89 & 0 \\
E: Awareness-raising activities & 27 & 1 \\
F: Mega-structure of a print dictionary & 20 & 0 \\
G: Overview of dictionary types and functions & 78 & 2 \\
H: Symbols and information features of dictionary & 29 & 7 \\
I: //Grammatical symbols & 6 & 2 \\
J: Terminology and lexical concepts & 6 & 23 \\
K: //What are collocations (and the collocations dictionary)? & 5 & 8 \\
\hline
\end{tabular}


interest. Some of the teachers learned the concept of collocation for the first time through this course when they looked at collocations dictionaries; others had never realized until this course that dictionary examples present collocational information. Some activities relating to 'Symbols and information features of a dictionary' seemed to help in increasing not only the teachers' dictionary knowledge, but also their language awareness.

\subsection{Teachers' evaluation of the course}

The results derived from the delayed follow-up questionnaire provided evidence as to the second research questions: how do teachers respond to the dictionary skills training course? In terms of the change in behavior, the training course brought about the greatest impact on the teachers' own dictionary consultation-with $74 \%$ of the teachers reporting having practised some of the skills they learned from the course. As to the teaching of dictionary skills, the result shows that half of the teachers $(50 \%)$ had passed on some of the learned skills to their students. On the other hand, slightly under half of the teachers (44\%) actually purchased or started using the dictionaries to which they had been introduced during the course. The area which had the lowest impact on the teachers' behavior was the integration of skills into teaching materials/classroom activities. Only three primary and two secondary teachers (15\% of the respondents) reported having applied what they learned from the course to designing teaching materials or activities.

The teachers' attitude toward English dictionaries underwent dramatic change in terms of motivation and interest. The absolute majority of the teacher-informants (94\%) reported that after the course they became willing to more fully exploit dictionaries for their learning of English, and more than $88 \%$ of them reported that they had more interest in English dictionaries.

The impact of the training course on teachers' professional development was also quite impressive; $94 \%$ of the teachers reported that the course was useful/very useful for their professional development as English teachers. Also, $91 \%$ of them agreed or strongly agreed that what they had learned in the course was useful for their own learning of English and their teaching. As to the last questionnaire item, asking if they would recommend colleagues to take the course, $80 \%$ responded in the positive. The difficulty and the excessive amount of the content were found to be the main drawbacks of the course.

\section{Conclusion and suggestions}

Within the framework of curriculum development project, this study investigated various aspects of Korean EFL teachers' dictionary training needs. From this study, it was found that typological and critical knowledge about dictionaries as well as electronic search techniques can be very effectively acquired through explicit dictionary training. Particularly, the enthusiasm and appreciation expressed by the trainee-teachers when they learned advanced electronic search functions and the 
most recent production-purpose dictionaries were a clear indication of the educational potential.

The study found that the skills which the teachers were most curious about tended to be related to the knowledge about, rather than of, using dictionaries. One noteworthy exception here was the lesson in electronic dictionaries. The session on electronic dictionaries included various locating skills. This shows that many of the competitive advantages of electronic dictionaries are under-exploited even by experienced dictionary users like the teachers in this study. Thus, particularly in this skill area, further efforts to reduce the gap between the sophistication of dictionary products and the skills of the user are called for in the pedagogy of dictionary use.

When we consider the uncertainty about some aspects of dictionary use that the teachers expressed in their open-ended questions, some of the dictionary skills and knowledge seem to be less likely to be acquired simply through users' steady interactions with dictionaries. They involve conscious decision-making, informed choice, and evaluation, identification of linguistic needs and purposeful dictionary consultation. They also require users to take the initiative to search dictionary products available in various forms and types for the ones which best suit their needs. As Chi (2003, p. 2) points out, it may be unrealistic to believe that these stages come spontaneously. Thus, explicit teacher training can provide an opportunity where teachers are introduced to the riches of English dictionaries and explore their diverse functions and facilities for learning.

The during-course analysis of teachers' dictionary knowledge needs via the session feedback is thought to have its own advantage in that it provides justification for teaching specific dictionary skills not on the basis of the teachers' ignorance of the predetermined target skills, but of whether the teachers actually recognized them as useful.

The dictionary course has gone through several stages of revision and modification afterward. The problems related to difficulty and content quantity were overcome by reducing substantial amount of classroom activities in the Week One and Week Two sessions. Discussions about dictionary reference skills were eliminated from the syllabus and the explicit introduction to dictionary terminology was kept to a minimum. Even though there is a clear dominance of electronic dictionary use, the tangibility of print dictionaries did sometimes have a great educational advantage, particularly when the teachers were learning the structure of a dictionary at the mega-structural level, and when they were acquainting themselves with unfamiliar dictionary types. Therefore, I decided to allocate more time for teachers to browse the dictionaries themselves, at the expense of reducing the amount of language-oriented tasks with these dictionaries.

As this study attempts a narrow yet detailed description of dictionary training needs of a particular teacher group, it should be acknowledged that there are several issues for consideration when we relate the results to contexts outside this study. The course proposed in this paper might have greater relevance to EFL teachers who share characteristics similar to those who participated in this study. Current orientation toward communicative classroom is obviously placing substantial demands on non-native English teachers, and many Korean teachers of English are still afraid of teaching all in English. Presumably, this situation is similar in other 
countries where English is hardly used outside the English classroom, and where the majority of school teachers have learned English largely for receptive purposes. Dictionary training can be highly compatible with in-service language skills courses for such non-native English teachers; by raising teachers' awareness of the rich resources of information provided by state-of-the-art dictionaries, it will help them become more autonomous and spontaneous users of English in a wider range of communicative situations. It is hoped that this research project lays the ground for further research activities and practices in the teaching of dictionary use.

\section{Appendix 1 Inventory of target reference skills for Korean EFL teachers}

Reference skills for Korean EFL teachers

Stage one: before study

1. The teachers understand different types of English dictionaries for learners and their specific purposes

(1) General purpose monolingual English dictionaries for learners

(2) English-Korean dictionaries

(3) English dictionaries for production: collocations dictionaries, thesauruses, and Language Activator

(4) Specialised English dictionaries: phrasal verbs and picture dictionaries

(5) Productive bilingual dictionaries: Korean-English dictionaries

(6) On-line dictionaries, personal hand-held dictionaries, mobile dictionaries, and dictionaries on CDROM

2. They understand organizations of dictionaries:

(1) Alphabetically organized dictionaries

(2) Thematically organized dictionaries

(3) Lexical resources not in dictionary form (corpora, Google search, etc.)

3. They understand the most typical false notion about dictionary types

4. They understand that reference skills are required for successful dictionary use

Stage two: before dictionary consultation

5. They understand typical communication situations where a specific kind of dictionary is more useful than the others. They can relate each situation to the most appropriate type of dictionary

6. They become aware of strategic uses of dictionaries (i.e., the danger of over-reliance of dictionaries during reading or writing)

7. They understand the importance of decision-making regarding what and how to search

Stage three: locating entry information

8. They understand the mega-structure of the dictionary: front matter, body, back matter, and their typical information components

9. They can find a target entry using various electronic search functions:

(1) Wildcards (* and ?)

(2) Approximate search

(3) Search by Korean script (keying a target word in Korean pronunciation)

10. They can find the entry for a multi-word unit by searching an exact sequence of words 
Reference skills for Korean EFL teachers

11. They understand the cross-reference system in print dictionaries

12. They understand the use of hyper-linking in electronic dictionaries

13. They can locate multi-media information (i.e., sounds, pictures, images, animations) in electronic dictionaries

14. They can locate target information outside the headword lists (electronic dictionaries)

(1) Using Boolean search (AND, OR, NOT)

(2) Searching within fields other than headwords

(3) Searching appendices and study guides

(4) Hypertexts

Stage four: interpreting entry information

15. They understand the micro-structure of the dictionary: an entry structure and its components

16. They can refer to signposts (guide words) for finding the right sense

17. They understand typographical conventions and the use of symbols, numbered superscripts, punctuation in the dictionary

18. They can interpret etymological information

19. They can interpret morphological and syntactic information and apply it appropriately to the context

20. They can interpret information about collocations

21. They can identify relevant information in examples

22. They can interpret restrictive labels

23. They can make use of additional dictionary information (in usage notes, appendices, or through hyperlinks) to enhance learning and communication

Stage five: recording entry information

24. They can use recording functions available in electronic dictionaries (menus such as my topic, my dictionary, memo, history, etc. available in most electronic dictionaries)

25. They understand the effective use of dictionaries for vocabulary learning (sifting useful information for further study, recording what they have found from a dictionary in their vocabulary notebook, etc.)

Stage six: understanding lexicographical issues

26. They can compare entries from the same type of dictionaries and decide which one is the most appropriate for their students' level, age, and interest

27. They understand different defining styles between monolingual learners' dictionaries and evaluate its relevance to their students

28. They appreciate the different principles and functions between monolingual dictionaries for native speakers of English and those for learners of English

29. They can evaluate content and organization of different electronic dictionaries in terms of their advantages and disadvantages

30. They acquire a balanced view about the role of dictionaries in the learning of a foreign language and can make informed choices regarding when and how to use dictionary information for what 


\section{Appendix 2 Coding summary of during-course session feedback}

\begin{tabular}{|c|c|c|c|c|}
\hline Classification & $\begin{array}{l}\text { Thematic } \\
\text { Category }\end{array}$ & & Code name & $\begin{array}{l}\text { Number of } \\
\text { references } \\
\text { coded }\end{array}$ \\
\hline \multirow[t]{35}{*}{ Teacher's opinions } & About the course & & & (100) \\
\hline & & 1 & Alienated teachers & 3 \\
\hline & & 2 & Expectations about the course & 28 \\
\hline & & 3 & //Dictionary activities & 9 \\
\hline & & 4 & Further questions about the lesson & 10 \\
\hline & & 5 & Questions relating to dictionary use & 13 \\
\hline & & 6 & //Dictionary use and learning of English & 8 \\
\hline & & 7 & Suggestions for improvement of the course & 43 \\
\hline & & 8 & //More examples & 4 \\
\hline & & 9 & //More hands-on practice & 11 \\
\hline & & 10 & //More online or electronic & 6 \\
\hline & & 11 & //More practical elements & 8 \\
\hline & & 12 & //More task guidance & 3 \\
\hline & & 13 & //Other suggestions for improvement & 10 \\
\hline & & 14 & Uncertain about the purpose of course & 4 \\
\hline & Negative feedback & & & (140) \\
\hline & & 15 & Difficult & 38 \\
\hline & & 16 & Excessive amount of course content & 25 \\
\hline & & 17 & Inappropriate time management & 7 \\
\hline & & 18 & Not interesting (boring) & 15 \\
\hline & & 19 & Not relevant to classroom pracice & 17 \\
\hline & & 20 & Teacher-centered lectures & 3 \\
\hline & & 21 & Tiring & 19 \\
\hline & & 22 & Unclear & 16 \\
\hline & Positive feedback & & & (563) \\
\hline & & 23 & Confidence increased & 13 \\
\hline & & 24 & Fun activities & 24 \\
\hline & & 25 & Knowledge and skills increased & 199 \\
\hline & & 26 & //Dictionary skills increased & 19 \\
\hline & & 27 & New knowledge gained & 65 \\
\hline & & 28 & Motivation increased & 37 \\
\hline & & 29 & Perspective modified & 87 \\
\hline & & 30 & Satisfaction with the course & 60 \\
\hline & & 31 & Useful for English learning & 24 \\
\hline & & 32 & Useful for English teaching & 35 \\
\hline
\end{tabular}




\begin{tabular}{|c|c|c|c|}
\hline Classification & & Code name & $\begin{array}{l}\text { Number of } \\
\text { references } \\
\text { coded }\end{array}$ \\
\hline \multirow[t]{11}{*}{ Skill areas } & A: & Comparing entries & \\
\hline & B: & Dictionaries for production & \\
\hline & C: & Discussion on Dictionary reference skills & \\
\hline & D: & Electronic dictionaries & \\
\hline & E: & Awareness-raising & \\
\hline & F: & Mega-structure of a print dictionary & \\
\hline & G: & Overview of dictionary types and functions & \\
\hline & $\mathrm{H}:$ & Symbols and information features of dictionary & \\
\hline & I: & //Grammatical symbols & \\
\hline & $\mathrm{J}:$ & Terminology and lexical concepts & \\
\hline & $\mathrm{K}:$ & //What are collocations? & \\
\hline \multirow{3}{*}{$\begin{array}{l}\text { Comments about specific } \\
\text { dictionaries }\end{array}$} & & Interest in particular dictionaries & 33 \\
\hline & & Specific dictionaries not useful & 9 \\
\hline & & Using print dictionaries & 24 \\
\hline
\end{tabular}

\section{References}

\section{Dictionaries}

Collins Cobuild English dictionary for advanced learners. 6th ed. (COBUILD). 2009. Ed. Joe Dougherty. Boston, MA: Heinle Cengage Learning.

Longman dictionary of contemporary English. 5th ed. (LDOCE). 2009. Ed. Michael Mayor. Harlow: Pearson Education.

Longman essential activator. 2nd ed. 2006. Ed. Della Summers. Harlow: Pearson Education.

Macmillan phrasal verbs plus. 2005. Eds. Michael Rundell and Gwyneth Fox. Oxford: Macmillan Education.

Macmillan English dictionary for advanced learners. 2nd ed. (MEDAL). 2007. Eds. Michael Rundell and Gwyneth Fox. Oxford: Macmillan Education.

Neungryule junior English dictionary. 2008. Seoul: Neungryule Education.

Oxford advanced learner's dictionary of current English. 8th ed. (OALD). 2010. Eds. Joanna Turnbull, Diana Lea, and Dilys Parkinson. Oxford: Oxford University Press.

Oxford advanced learner's English-Korean dictionary. 2008. Ed. Salley Wehmeier. Translated by Jeong Young-kuk and Cho Mi-ok. Seoul: Oxford University Press.

Oxford collocations dictionary for students of English. 2nd ed. 2002. Eds. Colin McIntosh and Ben Francis. Oxford: Oxford University Press.

Oxford learner's thesaurus: a dictionary of synonyms. 2008. Ed. Diana Lea. Oxford: Oxford University Press.

Oxford picture dictionary. English/Korean 2nd ed. 2008. Eds. Norma Shapiro and Jayme AdelsonGoldstein. Oxford: Oxford University Press. 


\section{Other publications}

Akasu, Kaoru and Satoru Uchida. 2011. Lexicography: Theoretical and practical perspectives. Papers submitted to the seventh ASIALEX Biennial International Conference, Kyoto, August 22-24. The Asian Association for Lexicography.

Bae, Susanna. 2011. Teacher-training in dictionary use: Voices from Korean teachers of English. In Lexicography: Theoretical and practical perspectives, eds. Akasu, Kaoru, and Satoru Uchida, 46-55.

Béjoint, Henri. 1989. The teaching of dictionary use: Present state and future tasks. In Dictionaries: An international encyclopedia of lexicography, eds. Hausmann, F.J., Reichmann, O., Wiegand, H E., and Zgusta, L., 208-215. Berlin: Walter de Gruyter.

Béjoint, Henri. 2010. The lexicography of English. Oxford: Oxford University Press.

Bogaards, Paul. 1993. Models of dictionary use. In Dutch Contributions to AILA'93, 17-28. Amsterdam: Free University.

Carduner, Jessie. 2003. Productive dictionary skills training: What do language learners find useful? Language Learning Journal 28:70-76.

Chi, Amy M.L. 2003. An empirical study of the efficacy of integrating the teaching of dictionary use into a tertiary English curriculum in Hong Kong. Hong Kong: Language Centre, Hong Kong University of Science and Technology.

Chi, Amy M.L. 2011. When dictionaries support vocabulary learning, where to begin? In Lexicography: Theoretical and practical perspectives, eds. Akasu, Kaoru, and Satoru Uchida, 76-85.

Cowie, Anthony (ed.). 1987. The dictionary and the language learner. Tübingen: Niemeyer.

Cowie, Anthony. 1983. The pedagogical/learners' dictionary: English dictionaries for the foreign learner. In Lexicography: Principles and practice, ed. Hartmann, R.R.K., 135-144. London: Academic Press.

de Schryver, Gilles-Maurice. 2003. Lexicographers' dreams in the electronic-dictionary age. International Journal of Lexicography 16(2):143-199.

Fichman, Pnina. 2011. A comparative analysis of answer quality on four question answering sites. Journal of Information Science 37(5):476-486.

Harmer, Jeremy. 2001. The practice of English language teaching. Harlow: Pearson Education.

Hartmann, Reinhard R.K., and James, Gregory. 1998. Dictionary of lexicography. London: Routledge.

Hartmann, Reinhard R.K. 2001. Teaching and researching lexicography. Harlow: Pearson Education.

Herbst, Thomas, and Gabriele, Stein. 1987. Dictionary-using skills: A plea for a new orientation in language teaching. In The dictionary and the language learner, ed. Cowie, Anthony, 115-127.

Horsfall, Philip. 1997. Dictionary skills in MFL 11-16. Language Learning Journal 15:3-9.

Hutchinson, Tom, and Waters, Alan. 1987. English for specific purposes. Cambridge: Cambridge University Press.

Jeong, Chanyong. 2004. Yeong-eo gongbu jeoldaero hagi mara [Never Ever Study English]. Seoul: Social Criticism.

Kwary, Deny, Nur Wulan and Lilla Musyahada. 2013. Lexicography and dictionaries in the information age. Selected papers from the 8th ASIALEX International Conference, Bali, August 20-22. Surabaya: Airlangga University Press.

Lee, Hun, and Lee, Jiyoung. 2006. Doseokwan yeong-eo dokseo-beop [Read English in libraries]. Seoul: Media Will.

Lew, Robert. 2013. From paper to electronic dictionaries: Evolving dictionary skills. In Lexicography and dictionaries in the information age, ed. Kwary, Deny, 79-84. Musyahada: Nur Wulan and Lilla.

Moulin, André. 1987. The place of the dictionary in an EFL programme. In The dictionary and the language learner, ed. Cowie, Anthony, 97-114.

Nation, I.S.Paul. 2013. Learning vocabulary in another language, 2nd ed. Cambridge: Cambridge University Press.

Nation, I.S.Paul. 2013. Learning vocabulary in another language, 2nd ed. Cambridge: Cambridge University Press.

Nesi, Hilary. 1999. The specification of dictionary reference skills in higher education. In Dictionaries in language learning. Recommendations, National Reports and Thematic Reports from the Thematic Network Project in the Area of Languages, Sub-Project 9: Dictionaries, ed. Reinhard, R.K. Hartmann, 53-67. Berlin: Free Universtiy/FLC/TNP. 
Nesi, Hilary. 2010. The virtual vocabulary notebook: The electronic dictionary as vocabulary learning tool. In Developing academic literacy, ed. George M. Blue, 213-226. London: Peter Lang.

Oh, Hee-jeong. 2006. Korean English teachers' use of English dictionaries and instruction on their use. Foreign Languages Education 13(3):419-443.

Ozawa, Shinya, and James, Ronald. 2009. Electronic dictionaries in the classroom. In Perspectives in lexicography: Asia and beyond, eds. Vincent Ooi, Ann Pakir, Ismail Talib and P.K.W. Tan, 129-137. Tel Aviv: K Dictionaries ltd.

Pastor, Véronica, and Alcina, Amparo. 2010. Search techniques in electronic dictionaries: A classification for translators. International Journal of Lexicography 23(3):307-354.

Richards, Jack. 2001. Curriculum development in language teaching. Cambridge: Cambridge University Press.

Saldaña, Johnny. 2009. The coding manual for qualitative researchers. London: Sage.

Scholfield, Phil. 1982. Using the English dictionary for comprehension. TESOL Quarterly 16:185-194.

Scholfield, Phil. 1999. Dictionary use in reception. International Journal of Lexicography 12(1):13-34.

Scholfield, Phil. 2002. Dictionaries. Subject Centre for Languages, Linguistics and Area Studies: University of Southampton. http://www.llas.ac.uk/resources/gpg/229. Accessed 20 June 2010.

Stark, Martin. 1990. Dictionary workbooks. Exeter: University of Exeter Press.

Whitcut, Janet. 1986. The training of dictionary users. In Lexicography: An emerging profession, ed. Robert Ilson, 111-121. Manchester: Manchester University Press. 